\title{
COMENTARIOS A APUNTES PARA LA HISTORIA DE LA OFTALMOLOGÍA DOMINICANA
}

\author{
LÓPEZ DE LETONA C ${ }^{1}$
}

Ha llegado hasta nosotros un interesante libro editado en la isla de Santo Domingo, su autor es el Dr. Heribert Stern Diaz y su título es precisamente el que encabeza nuestro presente artículo.

La obra, que se divide en catorce capítulos, se ordena por orden cronológico desde 1492 hasta el presente. Se dedican algunos apartados a la fundación de la Sociedad Dominicana de Oftalmología, puesta en marcha en los últimos años de la sexta década del siglo XX, si bien no llegó a funcionar de modo efectivo hasta los años setenta.

Pero de comienzo se nos informa de la existencia de la isla Hispaniola, que más adelante abarcaría dos naciones distintas: Haití y la actual Santo Domingo. Allí llegó Cristóbal Colón en 1492 en su primer viaje transoceánico y volvería en algunos de los otros que realizó.

También nos hace saber nuestro texto que en 1498 cuando ya iba el Almirante por su tercera singladura y estaba cerca de la actual Cuba (Que llamaron «La boca del Drago»), sufrió una grave «fluxión» en los ojos. Muy probablemente se trataba de una conjuntivitis. A causa de esta afección debió dirigirse a la Hispaniola, tal como relata el Padre Bartolomé de las Casas.

Concretamente Colón andaba afectado de la vista «De no dormir, por que siempre andaba entre tantos peligros y tantas islas y cuando descubrio lo que el pensaba era tierra firme, que resulto ser la isla de Cuba, se le llenaron los ojos de sangre».

Esta misma noticia es recogida por otro historiador de prestigio, Salvador de Madariaga, quien afirma que el propio Colón escribió en su diario lo siguiente: «Levanté las anclas por que andaba mucho deprisa por remediar los mantenimientos y también por remediarme a mi que habia adolecido por el desvelar de los ojos».
Los únicos facultativos que le trataron en esta afección ocular, que le acompañó toda la vida, fueron el Doctor Álvarez Chanca, primer médico enviado por los Reyes Católicos y el maestre cirujano Rodrigo Fernández.

A lo largo de los siguientes siglos, al panorama oftalmológico de la isla de Santo Domingo, fue bastante pobre estando casi toda la sanidad en manos de curanderos o simples empíricos, sin ninguna clase de titulación que utilizaban viejos remedios vegetales para curar diversos procesos patológicos de caracter oftalmológico.

Será a partir del siglo XIX cuando comiencen a mejorar algo las cosas en el país caribeño, debido en parte a que se afincaron allí diversos profesionales sanitarios procedentes de otros países.

Fue el caso de los médicos cubanos Alfredo Morales y Wenceslao Medrano y del español Basilio Íñiguez, licenciado en Madrid, quien a partir de 1861 fundó por su cuenta y riesgo un instituto sanitario en el que se enseñaba medicina así como la curación de determinadas afecciones oftálmicas.

Es por entonces cuando se funda la facultad médica en Santo Domigo la cual llevó una vida bastante irregular.

Ya en el siglo XX y concretamente en 1905 apareció la primera publicación médica dominicana que se tituló genéricamente Revista Médica, allí aparecieron algunos artículos en relación con nuestra especialidad.

También en la obra que estamos comentando se nos informa de la existencia de un importante precursor oftalmólogo, se trata del Dr. Emilio Rodríguez Oca. Nacido en 1888 es médico en 1913 estableciéndose definitivamente en la isla tras varios viajes al extranjero en 1920.

Otras figuras importantes, son Federico Ellis Cambiazo, Alejandro Grullon y más adelante

1 IOBA. Valladolid. España.

E-mail: berta@ioba.med.uva.es 
Miguel A. Garrido; del mismo modo Manuel E. Valdez Guerrero.

Pero siempre están presentes en todo el panorama sanitario de la isla los frecuentes cambios políticos que se producían y sobre todo la precariedad de las estructuras sanitarias casi inexistentes y confiadas en muchas ocasiones a médicos particulares casi carentes de recursos económicos.

También queremos referirnos a la fundación de la Sociedad Dominicana de Oftalmología. Sus primeros atisbos son de 1967 con ocasión de la celebración de un Symposiun relacionado con el glaucoma. Fue entonces cuando se sentaron las bases de dicha sociedad siendo sus componentes los no muy numerosos oftalmólogos recidentes en la isla.

Al principio todo se limitaba a muy modestas reuniones de oftalmólogos que casi tenían carácter de tertulia. El lugar elegido eran los domicilios particulares de los facultativos.

Corría ya 1974 cuando se publicaron definitivamente los estatutos de la Sociedad, siendo el Dr.
Ernesto Gómez Sánchez, quien solicitó a los poderes públicos los pertinentes permisos para que la Sociedad comenzase a funcionar definitivamente.

Se nos da también noticia de los diversos presidentes con los que ha contado la Asociación, teniendo siempre en cuenta que el cargo se renovaba anualmente; entre otros son los siguientes: antes de 1974: Manuel Eduardo Vélez Guerrero, Óscar Batlle Morel o Juan Díaz Espinal.

A partir de 1974 Ernesto Gómez Sánchez y posteriormente entre otros: Francisco Díaz Sosa (197576), Octavio Sánchez Perdomo (1976-77), de nuevo Ernesto Gómez Sánchez (1981-82) y pronto una mujer Miriam González de Alcántara (1984-85).

En los últimos años ocuparon el cargo Carlino Gonzalez Gil, Margarita Arbaje y Faroche Melgen Acra.

La verdad es que el panorama oftalmológico dominicano es muy diferente a nuestros conceptos europeos, pero pensamos que es bueno que al menos tengamos noticia de los que ocuur en otros lugares de la comunidad científica mundial. 